\title{
Identification of Novel Polyfluorinated Ether Sulfonates as PFOS Alternatives in Municipal Sewage Sludge in China
}

\author{
Ting Ruan, ${ }^{\dagger}$ Yongfeng Lin, ${ }^{\dagger}$ Thanh Wang, ${ }^{\ddagger}$ Runzeng Liu, ${ }^{\dagger}$ and Guibin Jiang* ${ }^{\dagger}$
}

${ }^{\dagger}$ State Key Laboratory of Environmental Chemistry and Ecotoxicology, Research Center for Eco-Environmental Sciences, Chinese Academy of Sciences, Beijing 100085, China

${ }^{\ddagger}$ Man-Technology-Environment (MTM) Research Centre, Örebro University, 70281 Örebro, Sweden

Supporting Information

ABSTRACT: A 6:2 chlorinated polyfluorinated ether sulfonate (6:2 Cl-PFAES) with the trade name F-53B, is an alternative to perfluorooctanesulfonate (PFOS) in electroplating industry that is uniquely used in China. It was developed as a mist suppressant initially in the 1970s, but the environmental behaviors and potential adverse effects of the 6:2 Cl-PFAES have only recently been investigated. In this work, the occurrence and distribution of perfluoroalkyl sulfonate (PFSA), fluorotelomer sulfonate (FTSA), and PFAES analogues were investigated in municipal sewage sludge samples collected around China. Perfluorobutane, perfluorohexane, perfluorooctane, and perfluorodecanesulfonates, 6:2 and 8:2 FTSAs, and the emerging 6:2 Cl-PFAES were detected. Moreover, 8:2 and 10:2 Cl-PFAESs were identified for the first time as new polyfluorinated contaminants using high resolution mass spectrometry. These fluorinated analytes were further quantified with the aid of commercial and laboratory-purified standards. PFOS was the predominant contaminant with a geometric mean (GM) value of $3.19 \mathrm{ng} / \mathrm{g}$ dry weight (d.w.), which was subsequently followed by 6:2 Cl-PFAES and 8:2 ClPFAES (GM: 2.15 and $0.50 \mathrm{ng} / \mathrm{g}$ d.w., respectively). Both 6:2 and 8:2 Cl-PFAES were positively detected as the major components in the F-53B commercial product, and discrete 6:2 Cl-PFAES/8:2 Cl-PFAES ratios in the product and sludge samples might suggest 8:2 Cl-PFAES had enhanced sorption behavior in the sludge due to the increase in hydrophobicity.

\section{INTRODUCTION}

Per- and polyfluoroalkyl substances (PFASs) are a group of anthropogenic chemicals, which have been subjected to increased public scrutiny in recent decades. The unique chemical properties of PFASs such as thermal resistance and high surface activity have led to extensive industrial and household applications, such as fire-fighting foams, lubricants, surfactants, pesticides, and coating additives. ${ }^{1,2}$ The unintentional releases of PFAS from direct manufacture emissions and daily usages as well as transport and transformation of polyfluorinated precursors ${ }^{3,4}$ have resulted in their ubiquitous presence in the environment and wildlife. ${ }^{5,6}$ In particular, perfluorooctanesulfonate (PFOS) has received the most attention because of the persistency, long-range transport potential, and bioaccumulation properties. $^{7-9}$ It displayed developmental, reproductive, and immunotoxic effects in both in vitro and in vivo studies. ${ }^{10}$ Thus, the production of PFOS was voluntarily phased out by major manufacturers in 2002 and has also been regulated under the Stockholm Convention on Persistent Organic Pollutants. ${ }^{11}$

Metal plating is an important emission source of PFOS industrial uses in China, in which commercial products containing PFOS (e.g., FC-80 and FC-248) are applied as mist suppressant to protect workers from exposure to airborne
Emerging Environmental Contaminants: Polyfluorinated Ether Sulfonates (PFAESs)
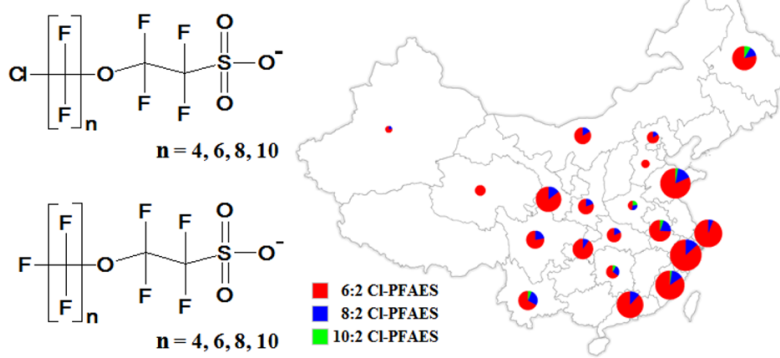

chromium(VI) spray mist in the electrolytic process. ${ }^{12}$ Owing to the lack of cost-effective alternatives, use of PFOS and its derivatives is still permitted as a specific exemption in closedloop systems of hard metal planting in certain countries. ${ }^{13}$ Nevertheless, additional polyfluorinated alternative substances, such as 6:2 fluorotelomer sulfonate (6:2 FTSA), are being tested at trial phase but with less efficiency in lowering the surface-tension and thus required more quantity/replenishment. ${ }^{14}$ China has been using polyfluoroalkyl ether sulfonates (PFAESs) as mist suppressant since the 1970s, even before the introduction of PFOS products, and is the only country with a documented usage of PFAESs. ${ }^{15}$ Potassium 1,1,2,2-tetrafluoro2-(perfluorohexyloxy) ethanesulfonate (6:2 F-PFAES with trade name F-53, Figure 1) was first synthesized and demonstrated to have excellent performance in electroplating at small-scale attempts, but the market share has since been dominated by the commercialized chlorine-substituted analogue, potassium 2-(6-chloro-1,1,2,2,3,3,4,4,5,5,6,6-dodecafluorohexyloxy)-1,1,2,2-tetrafluoroethanesulfonate (6:2 Cl-PFAES

Received: February 26, 2015

Revised: $\quad$ May 6, 2015

Accepted: May 11, 2015

Published: May 11, 2015 


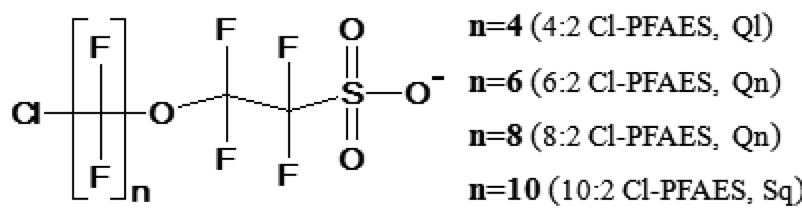

Chlorinated Polyfluorinated Ether Sulfonates (Cl-PFAESs)<smiles>O=S(=O)([O-])C(F)(F)C(F)(F)OC(F)(F)F</smiles>

$\mathbf{n = 4}(4: 2$ F-PFAES, Q1)

$\mathbf{n}=\mathbf{6}(6: 2$ F-PFAES, Q1)

$\mathbf{n}=\mathbf{8}(8: 2$ F-PFAES, Q1)

$\mathbf{n}=\mathbf{1 0}(10: 2$ F-PFAES, Q1)

\section{Perfluorinated Ether Sulfonates (F-PFAESs)}

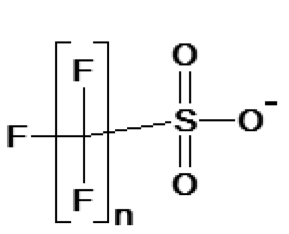

Perfluoroalkyl Sulfonates (PFSAs)

$$
\begin{aligned}
& \mathbf{n}=\mathbf{4}(\mathrm{PFBS}, \mathrm{Qn}) \\
& \mathbf{n}=\mathbf{6}(\mathrm{PFHx}, \mathrm{Qn}) \\
& \mathbf{n}=\mathbf{7}(\mathrm{PFHpS}, \mathrm{Qn}) \\
& \mathbf{n}=\mathbf{8}(\mathrm{PFOS}, \mathrm{Qn}) \\
& \mathbf{n}=\mathbf{1 0}(\mathrm{PFDS}, \mathrm{Qn})
\end{aligned}
$$

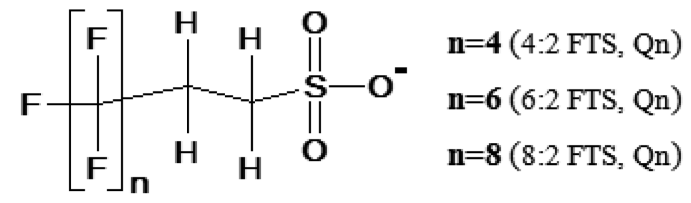

Fluorotelomer Sulfonates (FTSAs)

Figure 1. Chemical name, acronym, and molecular structures of target Cl-PFAES, F-PFAES, PFAS, and FTSA analogues. Types of instrumental analysis for each analyte are presented as qualitative $(\mathrm{Ql})$, semiquantitative $(\mathrm{Sq})$, and quantitative $(\mathrm{Qn})$, respectively.

with trade name F-53B), due to simplified production processes. $^{15,16}$ Although PFAESs have been used for several decades, scientific studies on the emission, environmental occurrence, and potential environmental impacts are still very limited. Wang and co-workers were the first to evaluate the potential impacts of 6:2 Cl-PFAES to the environment. ${ }^{16}$ Release of 6:2 Cl-PFAES was found in electroplating plant wastewater $(65-112 \mu \mathrm{g} / \mathrm{L}$ in the influent and $43-78 \mu \mathrm{g} / \mathrm{L}$ in the effluent). 6:2 Cl-PFAES showed moderate toxicity to Brachydanio rerio $\left(\mathrm{LC}_{50}(96 \mathrm{~h}) 15.5 \mathrm{mg} / \mathrm{L}\right)$ in acute toxicity assay and was resistant to biodegradation. Nevertheless, contamination trends and distribution patterns of $6: 2 \mathrm{Cl}-$ PFAES in different environmental compartments as well as the occurrence and fate of other Cl-PFAES and F-PFAES analogues are still unclear.

Wastewater treatment plants (WWTPs) are commonly considered as major sinks of various groups of PFASs and is also an important secondary point source of these compounds to both the aquatic and atmospheric environment. ${ }^{17,18}$ The sorption of perfluoroalkyl sulfonates (PFSAs) onto suspended particulate matters indicates that sewage sludge could be used to track the presence, concentration, and fate of PFOS and analogous compounds due to human activities. The aims of this present work were (1) to establish a robust sample pretreatment and instrument quantification method for simultaneous analysis of PFSAs, FTSAs, and 6:2 Cl-PFAES in sludge samples; (2) to screen for identification of potential PFOS alternatives by using high resolution mass spectrometry suspect screening strategy; (3) to measure the residue concentrations and investigate the composition profiles of PFOS and alternatives in sewage sludge from different regions in China. To our knowledge, this study is the first to report the presence of novel PFAES analogues (8:2 Cl-PFAES and 10:2 Cl-PFAES) in the environment.

\section{MATERIALS AND METHODS}

Materials. Chemical name, acronym, structure, and other information for the target compounds are shown in Figure 1. A native PFBS, PFHxS, PFOS, and PFDS standard mixture (PFAC-MXB, $2 \mu \mathrm{g} / \mathrm{mL}$ for each analyte), native $\mathrm{PFHpS}$, individual native fluorotelomer sulfonates (4:2, 6:2 and 8:2 FTSA, $50 \mu \mathrm{g} / \mathrm{mL}$ for each analyte), and isotope-labeled internal standards (MPFHxS, M3PFHxS, MPFOS, M8PFOS, and M26:2 FTSA, $50 \mu \mathrm{g} / \mathrm{mL}$ for each analyte) were purchased from Wellington Laboratories (Ontario, Canada). 6:2 Cl-PFAES and 8:2 Cl-PFAES standards were laboratory-purified from the commercial F-53B mist suppressant product, and details on methodology and structural characterization procedures are given in the Supporting Information (SI). The purity of all chemicals were $95 \%$ or higher unless otherwise stated. HPLCgrade acetonitrile and methanol were supplied by J.T. Baker (Phillipsburg, NJ). Ultrapure water $(18.3 \mathrm{M} \Omega \cdot \mathrm{cm})$ was generated by a Milli-Q system (Millipore, Billerica, MA). ENVI-Carb powder (120-400 mesh, $100 \mathrm{~m}^{2} / \mathrm{g}$ ) was from Sigma-Aldrich (St. Louis, MO). Sodium hydroxide, concentrated hydrochloric acid (37\%), and ammonium acetate were obtained from Sinopharm Chemical Reagent, Inc. (Beijing, China), Merck (Darmstadt, Germany), and Dikma (Lake Forest, CA) separately.

Sampling and Extraction Procedures. Detailed sample collection processes have been published elsewhere, ${ }^{19}$ and the sampling locations are shown in Figure S1. In brief, a total of 56 grab sewage sludge samples were collected during October 2010 to May 2011 from individual wastewater treatment plants, covering 20 provinces and municipalities in China. Freshly digested sludge samples (approximately $500 \mathrm{~g}$ for each sample, wet weight, w.w.) from the WWTP dehydration process were packed in aluminum foil, sealed in polypropylene bags, and immediately express-delivered to our laboratory. The samples were then lyophilized, homogenized, and preserved at $-20{ }^{\circ} \mathrm{C}$ until analysis. Relevant information on the WWTP characteristics, i.e., type of treatment and daily processing volume, is summarized in Table S1.

The sample pretreatment was based on the dispersive solidphase extraction (DSPE) method for the analysis of PFASs in environmental matrices ${ }^{20,21}$ with slight modifications. In the primary DSPE procedure, approximately $0.5 \mathrm{~g}$ of individual sludge sample was placed in a $10 \mathrm{~mL}$ crimp neck glass vial with a rubber septa (CNW Technologies $\mathrm{GmbH}$, Dusseldorf, Germany), and $2 \mathrm{ng}$ of each surrogate standards (MPFHxS, MPFOS and M2-6:2 FTSA) was spiked to each sample. Alkaline organic solvent containing $3 \mathrm{~mL}$ of acetonitrile and $160 \mu \mathrm{L}$ of $1 \mathrm{M}$ sodium hydroxide solution were used to extract the analytes by shaking at $50{ }^{\circ} \mathrm{C}$ for $120 \mathrm{~min}$. After 
Table 1. Descriptive Statistics of the Measured PFAS Concentrations (ng/g d.w. Sludge) in the Investigated Sludge Samples

\begin{tabular}{|c|c|c|c|c|c|c|c|}
\hline \multirow[b]{2}{*}{ analyte } & \multirow[b]{2}{*}{$\mathrm{GM}^{a}$} & \multirow[b]{2}{*}{ median } & \multirow[b]{2}{*}{ 95th percentage } & \multirow[b]{2}{*}{ range } & \multirow[b]{2}{*}{ detection ratio ${ }^{b}(\%)$} & \multicolumn{2}{|c|}{ average proportion (\%) } \\
\hline & & & & & & in each analogue & in $\Sigma$ FASs \\
\hline \multicolumn{8}{|c|}{ Perfluoroalkyl Sulfonates (PFSAs) } \\
\hline PFBS & 0.24 & $0.10^{*}$ & 1.53 & N.D. -2.76 & 51.8 & 11.5 & 4.74 \\
\hline PFHxS & 0.15 & N.D. & 1.10 & N.D. -1.93 & 28.6 & 7.75 & 3.56 \\
\hline PFOS & 3.19 & 3.21 & 154 & N.D. -218 & 98.2 & 76.5 & 39.8 \\
\hline PFDS & 0.09 & N.D. & 0.62 & N.D. -0.94 & 19.6 & 4.30 & 1.87 \\
\hline$\Sigma$ PFSAs & 4.38 & 4.42 & 154 & N.D. -220 & 98.2 & 100 & 50.0 \\
\hline \multicolumn{8}{|c|}{ Chlorinated Polyfluoroalkyl Ether Sulfonates (Cl-PFAESs) } \\
\hline 6:2 Cl-PFAES & 2.15 & 1.94 & 78.7 & $0.02 *-209$ & 100 & 75.9 & 30.1 \\
\hline 8:2 Cl-PFAES & 0.50 & 0.43 & 14.0 & N.D. -31.8 & 89.3 & 19.8 & 7.17 \\
\hline 10:2 Cl-PFAES & 0.07 & N.D. & 0.56 & N.D. -0.86 & 23.2 & 4.30 & 1.36 \\
\hline$\Sigma$ Cl-PFAESs & 2.86 & 2.51 & 92.7 & $0.31-241$ & 100 & 100 & 38.6 \\
\hline \multicolumn{8}{|c|}{ Fluotelomer Sulfonates (FTSAs) } \\
\hline $6: 2$ FTSA & 0.13 & 0.13 & 2.56 & N.D. -13.9 & 76.8 & 40.7 & 5.60 \\
\hline 8:2 FTSA & 0.23 & 0.28 & 1.52 & N.D. -5.08 & 89.3 & 59.3 & 5.79 \\
\hline$\Sigma$ FTSAs & 0.49 & 0.58 & 2.83 & N.D. -18.9 & 92.9 & 100 & 11.4 \\
\hline$\Sigma$ FASs & 10.5 & 8.07 & 167 & $1.12-413$ & 100 & & 100 \\
\hline
\end{tabular}

${ }^{a} \mathrm{GM}$ : geometric mean. ${ }^{b}$ Detection ratio: sample taken into account for each analyte when the instrument signal/noise $>3$.

centrifugation at $1600 \mathrm{~g}$ for $10 \mathrm{~min}$, part of supernatant $(600$ $\mu \mathrm{L}$ ) was placed into a $2 \mathrm{~mL}$ microcentrifuge tube (Axygen, Union city, CA) and mixed with $400 \mu \mathrm{L}$ of acetonitrile, $15 \mu \mathrm{L}$ of $1 \mathrm{M}$ sodium hydroxide solution and $10 \mathrm{mg}$ of ENVI-Carb powder for further pretreatment. The mixture was then shaken at $50{ }^{\circ} \mathrm{C}$ for $120 \mathrm{~min}$, while the supernatant was collected after centrifugation at $12000 \mathrm{~g}$ for $10 \mathrm{~min}$ and neutralized by addition of $15 \mu \mathrm{L}$ of $1 \mathrm{M}$ hydrochloric acid and $4 \mu \mathrm{L}$ of $1 \mathrm{M}$ ammonium acetate solution. In order to increase recovery of the target compounds in the residual sludge phase, a secondary DSPE cycle with the same operational steps was performed. All supernatant in the primary and secondary extraction was combined, concentrated to $200 \mu \mathrm{L}$ under a nitrogen stream, transferred into a LC vial, spiked with isotope-labeled injection standards (400 pg for M3PFHxS and M8PFOS, respectively), and shaken before instrument analysis.

Qualitative Analysis and Quantification Procedures. In order to positively detect the target fluoroalkyl sulfonate analytes as well as to identify other potential analogues in the sludge extracts, a high resolution mass spectrometry (HRMS) suspect screening strategy was performed. An ultrahigh performance liquid chromatography-Orbitrap Fusion MS system (Thermo Fisher Scientific Inc., Waltham, MA) was operated in full scan mode $(200-800 \mathrm{~m} / z)$ with a resolution of 120000 . The negative electrospray ionization (ESI) mode was chosen with a capillary voltage of $2500 \mathrm{~V}$. Ion transfer tube and vaporizer temperatures were respectively 350 and $200{ }^{\circ} \mathrm{C}$. The higher-energy collision dissociation (HCD) energy was optimized as $35 \%$. Presence of fluoroalkyl sufonates was confirmed by analysis of putative theoretical molecular ion masses in the full-scan spectrum data within a threshold of 5 part-per-million (ppm) accuracy (Table S2). Structural recognition was performed based on appropriate liquid chromatography retention time and characteristic $\mathrm{MS}^{2}$ fragmentation patterns with the aid of the PFSA, FTSA, and PFAES standards.

The quantification of targeted fluoroalkyl sulfonates was performed on a API 5500 triple-quadrupole mass spectrometer (AB SCIEX Inc., Framingham, MA) interfaced with an Ultimate 3000 ultrahigh performance liquid chromatograph (Thermo Fisher Scientific Inc., Waltham, MA). An ACQUITY
BEH C18 analytical column $(2.1 \mathrm{~mm}$ i.d. $\times 100 \mathrm{~mm}$ length, 1.7 $\mu \mathrm{m}$, Agilent) was used for separation. Column temperature was $35{ }^{\circ} \mathrm{C}$, and flow rate was set at $0.3 \mathrm{~mL} / \mathrm{min}$. The flow gradient was initiated at a composition of 60:40 (methanol/water, v/v, 1 $\mathrm{mM} \mathrm{NH}_{4} \mathrm{Ac}$ additive in each phase), held for $1 \mathrm{~min}$, linearly switched to $100 \%$ methanol in $5 \mathrm{~min}$, and the composition was finally held for another $2 \mathrm{~min}$. ESI ionization was operated in the negative mode with a capillary voltage of $3000 \mathrm{~V}$. Ionization source temperature was optimized at $500{ }^{\circ} \mathrm{C}$. Detailed multiple reaction monitoring (MRM) parameters, such as quantification ion transition, declustering potential and collision energy for each analyte, are summarized in Table S3.

Quality Assurance and Quality Control (QA/QC). Extraction efficiencies of the target analytes were checked by a third basic acetonitrile DSPE extraction procedure of 10 randomly selected sludge samples, and these extracts were separately pretreated and quantified. Less than $4.0 \%$ of PFOS and $0.8 \%$ of $8: 2$ Cl-PFAES were found in the third extract, indicating maximum extraction of the target analytes during the primary and secondary extraction cycles. Two procedural blanks of $0.5 \mathrm{~g}$ of solvent-washed diatomaceous earth (Dionex, Sunnyvale, CA) were included in each batch of seven sludge samples. All analytes in the blanks were under the method quantification limits (MQLs, Table S3), which were in the range of 25.2 (6:2 FTSA) to 135 (PFBS) pg/g sludge. No target analyte was found in the solvents nor the LC system. The recoveries of matrix-spiked samples $(n=3$, arithmetic mean \pm standard deviation) were $112 \pm 10,116 \pm 13$, and $109 \pm 14$ for PFSAs, FTSAs, and PFAESs at 2 ng spiked level, and were 110 $\pm 12,127 \pm 16$, and $93 \pm 6$ for PFSAs, FTSAs and PFAESs at 20 ng spiked level, respectively. Quantification was based on an internal calibration method. The recoveries of the surrogate standards $(n=3)$ were $91 \pm 7,95 \pm 3$, and $137 \pm 10$ for MPFHxS, MPFOS, and M2-6:2 FTSA at 2 ng spiked level, and were $92 \pm 3,95 \pm 5$, and $122 \pm 7$ for MPFHxS, MPFOS, and M2-6:2 FTSA at $20 \mathrm{ng}$ spiked level, respectively. Ionization enhancement was observed in the quantification analysis, as the matrix interferences of the injection standards were $161 \pm 18$ and $158 \pm 16$ for M3PFHxS and M8PFOS (each spiked at $400 \mathrm{pg}$ in the sample vials), separately. The dynamic range of the instrument responses were verified daily 
(A) 20ppb-standard-MSn-35eV \#2619-2651 RT: 6.69128-6.75097 AV: 5 NL: $1.02 E 6$ F: FTMS - c ESI Full ms2 630.89@hcd35.00 [50.00-750.00]

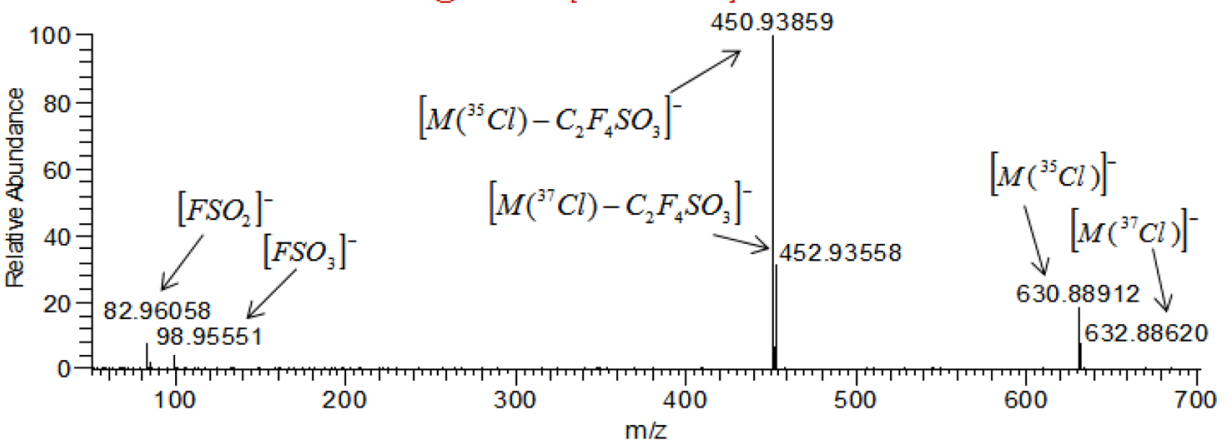

(B) 6:2 Cl-PFAES standard:

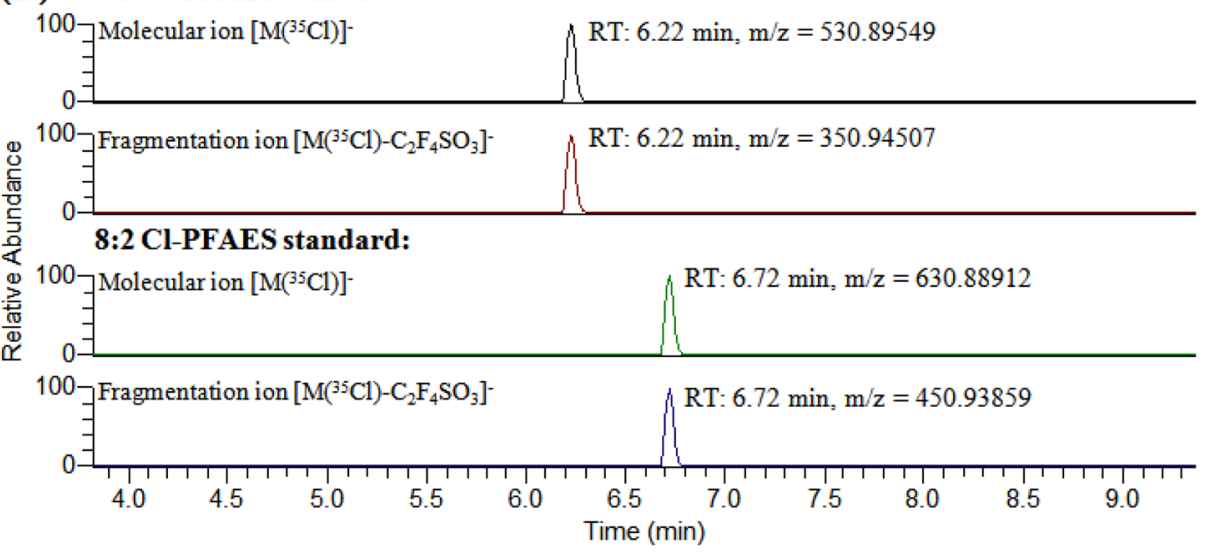

(C) 6:2 Cl-PFAES in sludge:

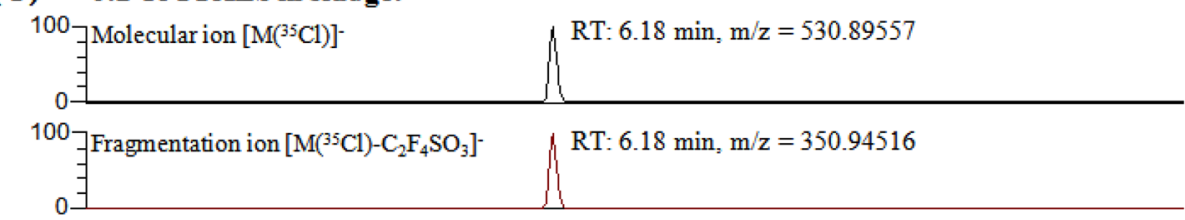

8:2 Cl-PFAES in sludge:

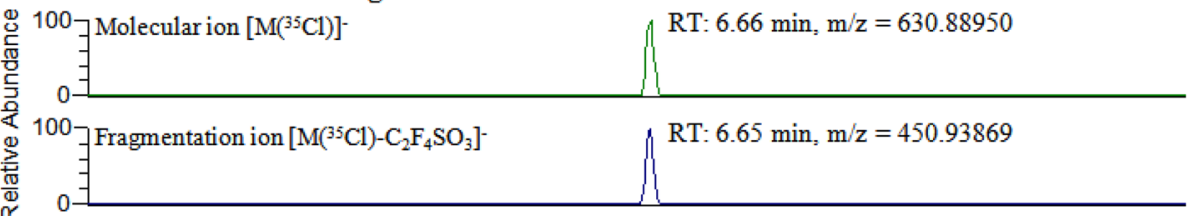

10:2 Cl-PFAES in sludge:

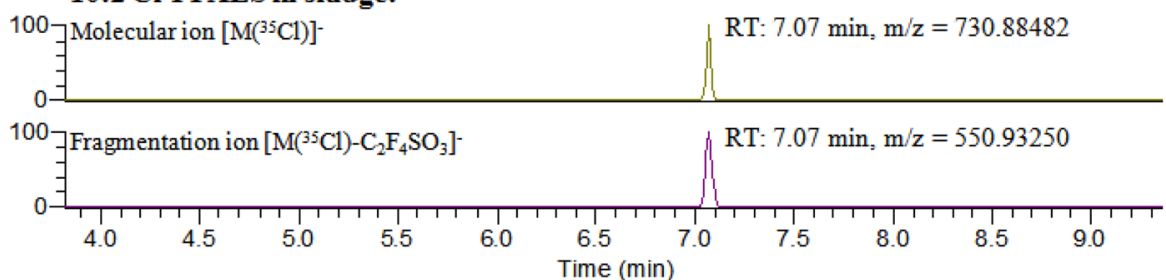

Figure 2. Accurate mass measurement, LC retention time, and $\mathrm{MS}^{2}$ fragmentation patterns of the identified Cl-PFAESs in the laboratory-purified standard and sludge samples. (A) MS ${ }^{2}$ characteristic fragmentation ions of the 8:2 Cl-PFAES standard in the HCD mode (collision energy: 35\%). (B) Reconstructed total ion chromatography of the molecular ion and fragmentation ion transits of individual 6:2 and 8:2 Cl-PFAES standards (spiked at $20 \mathrm{ng} / \mathrm{mL}$ for each analyte) with mass windows of theoretical mass $\pm 5 \mathrm{ppm}$. (C) Reconstructed total ion chromatography of the molecular ion and fragmentation ion transits of 6:2, 8:2, and 10:2 Cl-PFAES in a sludge sample with mass windows of theoretical mass \pm 5 ppm.

using a nine-point calibration curve with concentrations in the range of $0.1-50 \mathrm{ng} / \mathrm{mL}$. For samples with analyte concentrations beyond the quantification dynamic range, dilution was made by addition of acetonitrile containing both $2 \mathrm{ng} / \mathrm{mL}$ of M3PFHxS and M8PFOS injection standards, and the diluted extract was then reanalyzed. All reported data in this study is presented on a dry weight (d.w.) basis.

Statistical Analysis. Geometric mean, median, and concentration ranges were used to describe the results (Table 1). Nonquantifiable analyte concentrations with signal-to-noise 
less than 10 were set as MQL divided by the square root of 2 . All data were log-transformed in the Spearman's test to assess correlations among the analyte residue levels as well as the WWTP characteristic (i.e., sludge total organic carbon content). Principal component analysis was performed using the varimax rotation method with Kaiser normalization. Statistical analyses were conducted using SPSS V17.0 for Windows Release (SPSS, Inc., 2009), and significant levels were determined at $p<0.05$ level unless otherwise mentioned.

\section{RESULTS AND DISCUSSION}

Structure Confirmation of Novel PFAES Analogues. Accurate molecular mass and characteristic structure fragment ion are both diagnostic parameters for the identification of unknown organic contaminants, ${ }^{22}$ information on which could be simultaneously obtained in retrospect analysis of HRMS $\mathrm{MS}^{2}$ full scan spectrum. Thus, the fragmentation mechanisms of PFAESs were studied by using the 6:2 Cl-PFAES and 8:2 ClPFAES standards. The major fragmentation ions and the corresponding abundance of 6:2 Cl-PFAES in the HCD mode of the Orbitrap (Figure S2) were quite similar to those reported in the triple quadrupole (LC-MS/MS) instrument. ${ }^{16}$ For instance, cleavage of the ether bond in the molecular structure resulted in the most abundant characteristic ion $\left[\mathrm{M}\left({ }^{35} \mathrm{Cl}\right)\right.$ $\left.\mathrm{C}_{2} \mathrm{~F}_{4} \mathrm{SO}_{3}\right]^{-}$, and the formation of $\left[\mathrm{FSO}_{3}\right]^{-}$and $\left[\mathrm{FSO}_{2}\right]^{-}$could also provide additional information on the sulfate functional group. Similar abundance of $\left[\mathrm{M}\left({ }^{35} \mathrm{Cl}\right)-\mathrm{C}_{2} \mathrm{~F}_{4} \mathrm{SO}_{3}\right]^{-},\left[\mathrm{FSO}_{3}\right]^{-}$, and $\left[\mathrm{FSO}_{2}\right]^{-}$ions were found in 8:2 Cl-PFAES $\mathrm{MS}^{2}$ spectrum (Figure $2 \mathrm{~A}$ ), which indicates that the observed fragmentation pattern could be suitable for identifying other PFAES analogues. As shown in Figure 2C, accurate molecular ion $\left[\mathrm{M}\left({ }^{35} \mathrm{Cl}\right)\right]^{-}$and characteristic fragmentation ion $\left[\mathrm{M}\left({ }^{35} \mathrm{Cl}\right)\right.$ $\left.\mathrm{C}_{2} \mathrm{~F}_{4} \mathrm{SO}_{3}\right]^{-}$for both 6:2 Cl-PFAES $(\mathrm{m} / z=530.8956, \Delta m=$ $-0.021 \mathrm{ppm}$, and $m / z=350.9452, \Delta m=0.017 \mathrm{ppm}$, respectively) and 8:2 Cl-PFAES $(m / z=630.8895, \Delta m=$ $0.485 \mathrm{ppm}$, and $m / z=450.9387, \Delta m=-0.171 \mathrm{ppm}$, respectively) were discovered, indicating the presence of the analytes in the sludge extract. Moreover, 10:2 Cl-PFAES was also positively identified with lower instrument responses $(\mathrm{m} / \mathrm{z}$ $=730.8848, \Delta m=2.754 \mathrm{ppm}$, and $m / z=550.9325, \Delta m=$ $0.218 \mathrm{ppm}$ for $\left[\mathrm{M}\left({ }^{35} \mathrm{Cl}\right)\right]^{-}$and $\left[\mathrm{M}\left({ }^{35} \mathrm{Cl}\right)-\mathrm{C}_{2} \mathrm{~F}_{4} \mathrm{SO}_{3}\right]^{-}$ions, respectively) in the sludge matrix, which was further supported by predicted delay in LC retention time $(\mathrm{RT}=7.07 \mathrm{~min})$ compared with those of 6:2 Cl-PFAES and 8:2 Cl-PFAES standards (RT $=6.18$ and $6.65 \mathrm{~min}$, respectively). The recognition of $8: 2$ and 10:2 Cl-PFAES analogues could imply the impact of impurity component release into the environment from the F-53B product usages. Nevertheless, the characteristic $\mathrm{m} / z$ of 4:2 Cl-PFAES was not observed in any of the commercial product or sludge samples, indicating no practical usage of the chemical in China. The identification method was also used to check the presence of F-PFAES analogues (4:2, 6:2, 8:2, and 10:2 F-PFAES, Figure 1 and Table S2) in the sludge extracts. However, no signal corresponding to the accurate molecular mass or $\mathrm{MS}^{2}$ fragmentation ion was found for any of these analogues. This result confirms the suggestion in a previous report that F53 was replaced by F53B as the only commercial PFAES mist suppressant product in the market. ${ }^{16}$

PFSA Distribution. The quantification of PFSAs was performed by LC-MS/MS. PFBS, PFHxS, PFOS, and PFDS were positively detected in the sludge samples, while $\mathrm{PFHpS}$ was not found (method detection limit: $43 \mathrm{pg} / \mathrm{g}$ ). Descriptive statistic data of the measured PFSA concentrations are summarized in Table 1 . PFOS was the dominant PFSA with a geometric mean (GM) concentration of $3.19 \mathrm{ng} / \mathrm{g}$, which constitute $29-100 \%$ (average proportion: $76 \%$ ) of total PFSA levels ( $\Sigma$ PFSAs). This was followed by PFBS (average 11\%), PFHxS (average 7.8\%) and PFDS (average 4.3\%), with GM values of $0.24,0.15$, and $0.09 \mathrm{ng} / \mathrm{g}$, respectively. The PFOS contamination levels in sewage sludge have been extensively studied in numerous countries, e.g. Switzerland (concentration range: $20-600 \mathrm{ng} / \mathrm{g}$ d.w.), ${ }^{23}$ Denmark (4.8-71.4 ng/g d.w.), ${ }^{24}$ Sweden $(0.52-35 \mathrm{ng} / \mathrm{g}$ w.w. $){ }^{25}$ Canada $(0.1-460 \mathrm{ng} / \mathrm{g}$ d.w.), ${ }^{26}$ U.S. $\left(14-444 \mathrm{ng} / \mathrm{g}\right.$ d.w. ${ }^{27}$ and China $(0.5-19.8 \mathrm{ng} /$ g d.w.). ${ }^{28,29}$ A similar concentration range of $<$ LOD-218 ng/g was also found in this study. The PFSA concentrations in sludge are influenced by environmental factors such as adsorption and biotransformation during the WWTP treatment processes as well as the residue amount in sewage influent released from industry and household applications. ${ }^{3,17,27,30} \mathrm{Yu}$ and co-workers suggested that PFAS levels in sludge may be more relevant to the aqueous concentrations than sludge retention behaviors, ${ }^{31}$ even though more hydrophobic perfluorinated analogues have increased distribution coefficients (i.e., $K_{\mathrm{d}}$ values). ${ }^{32}$ Thus, the higher detection ratios of PFOS (98\%) and PFBS (52\%) in the sludge samples, compared with those of PFHxS (29\%) and PFDS (20\%), could indicate widespread usage of C8 and C4 PFSAs and relevant precursors in China. The finding was further supported by the reported uniform PFSA composition profiles in coastal rivers and marine sediments from Chinese territorial sea. ${ }^{33}$

PFAES Distribution. The concentrations of $6: 2$ and $8: 2 \mathrm{Cl}-$ PFAES in the sludge samples were quantified using the laboratory-purified standards. As 10:2 Cl-PFAES was also identified in the HRMS suspect screening strategy, semiquantification of 10:2 Cl-PFAES was further performed by applying the HRMS quantification strategy, which utilized the full MS scan spectrum and data-dependence $M S^{2}$ fragmentation ion for quantitative and qualitative purposes simultaneously. ${ }^{34}$ The instrument response factor of 10:2 Cl-PFAES was assumed to be equal to that of an equimolar amount of 8:2 Cl-PFAES in full-scan HRMS spectrum since those of 6:2 and 8:2 Cl-PFAES were found to be quite similar (Figure S3). 6:2 and 8:2 ClPFAES were the main analogues with GM concentrations of 2.15 and $0.50 \mathrm{ng} / \mathrm{g}$, which constitute $76 \%$ and $20 \%$ of total PFAES concentrations ( $\Sigma$ PFAESs), respectively. 10:2 ClPFAES was found in $23 \%$ of sludge samples with a GM concentration of $0.07 \mathrm{ng} / \mathrm{g}$, which only contributed to a very small part $(4.3 \%)$ of PFAES levels. The spatial concentrations and composition profiles of PFAES in different investigated regions are given in Figure $S 1$. It is obvious that uniform composition profiles of 6:2 and 8:2 Cl-PFAES were found in almost all of the sampling locations, which could suggest common usage and/or sources. The PFAES levels in sludge showed geographical variations with the highest levels in the eastern coastal provinces, which coincided with areas of more intensive metal plating activities. ${ }^{12}$ The limited knowledge on the environmental levels of PFAESs suggested considerable amounts of PFOS and 6:2 Cl-PFAES in electroplating plant wastewater and vicinity river samples. ${ }^{16}$ In this study, PFOS and 6:2 Cl-PFAES showed high detection ratio (98\% and $100 \%$, respectively) and similar maximum concentrations (218 and $209 \mathrm{ng} / \mathrm{g}$, respectively), which indicate universal usage of both chemicals. Nevertheless, the greater PFOS average proportion in total fluoroalkyl sulfonate concentrations ( $\Sigma$ FASs, $40 \%$ ) compared with that of the 6:2 Cl-PFAES 
Table 2. Spearman's Correlation Matrix for the PFAS Concentrations and WWTP Characteristics (TOC Content and Daily Processing Volume)

$\begin{array}{llllll} & \text { PFOS }^{a} & 6: 2 \text { FTSA } & 8: 2 \text { FTSA } & 6: 2 \text { Cl-PFAES } & \text { TOC Cl-PFAES } \\ \text { 6:2 FTSA } & & & \\ \text { 8:2 FTSA } & -0.085 & & & & \\ \text { 6:2 Cl-PFAES } & 0.263^{* c} & 0.198 & -0.001 & 0.849^{* *} & -0.240 \\ \text { 8:2 Cl-PFAES } & 0.372^{* *} & -0.103 & 0.095 & -0.157 \\ \text { TOC content } & 0.266^{*} & 0.076 & -0.016 & 0.110 & 0.110 \\ \text { processing volume } & 0.032 & 0.108 & 0.178 & 0.272^{*}\end{array}$

${ }^{a}$ Analytes with detection ratio less than $70 \%$ in the sludge samples were not taken into account. Concentrations under the MQLs were set as MQL divided by the square root of 2 . $^{b}$ All data were log-transformed. ${ }^{c}$ The symbols “*” and “**” represent the significant correlations at 0.05 and 0.01 levels, respectively.

(30\% in $\Sigma$ FASs), might imply more consumer usage amount and/or application purposes of PFOS in China regarding similar physical-chemical properties of the two compounds. ${ }^{16}$

FTSA Distribution. 6:2 and 8:2 FTSA were detected in most sludge samples with GM values of 0.13 and $0.23 \mathrm{ng} / \mathrm{g}$, respectively. Specific 4:2 FTSA signals were not found in the monitored qualitative/quantitative transitions of the LC-MS/ MS instrument. A high average proportion (59\%) of 8:2 FTSA found in this study was consistent with those reported in surface water and human blood in China. ${ }^{35}$ No specific regional difference in contamination levels was observed for FTSAs among the sampling sites, and the small contribution of $6: 2$ and 8:2 FTSA to $\Sigma$ FASs (5.6\% and 5.8\%, respectively), compared with those of PFSA and Cl-PFAES analogues (Table 1), imply relatively low usage of FTSA-based commercial products. FTSA residues in the environment were found to be mainly related with the aqueous film-forming foam (AFFF) applications instead of mist suppressant usage. ${ }^{36}$ FTSA was found to be present in some AFFF formulations, and significant release levels (up to $14600 \mathrm{ng} / \mathrm{L}$ ) of 4:2, 6:2, and 8:2 FTSA were detected in groundwater where fire-training activities were conducted. ${ }^{36}$ Degradation of fluorotelomer precursors is the primary FTSA source, ${ }^{37}$ and the elevated abundance of $8: 2$ FTSA on surfacial AFFF-impacted soil further suggest contributions of the C8 FTSA-based compounds in the environment. $^{38}$

Correlations between Fluorinated Sulfonates and Influencing Factors. The total fluoroalkyl sulfonate concentrations ( $\Sigma$ FASs, Table 1) were in the range of $1.12-413 \mathrm{ng} / \mathrm{g}$, with a GM concentration of $10.5 \mathrm{ng} / \mathrm{g}$. It consisted of $52 \pm$ $24 \%$ in overall PFAS contamination levels (including the target fluoroalkyl sulfonates and C4-C14 perfluoroalkyl carboxylates, data not shown) in the sludge samples. Among the target fluoroalkyl sulfonate analogues, PFSAs were the dominant chemicals with a relative proportion of $50 \pm 24 \%$ in $\Sigma$ FASs, which implied that the PFSA usages in China could result in a primary burden of fluoroalkyl sulfonate residues in the sludge samples. The relative abundance was subsequently followed by PFAESs and FTSAs, with relative proportions of $39 \pm 25 \%$ and $11 \pm 12 \%$ in $\Sigma$ FASs, respectively. As also noted in Table 2, the log-transformed PFOS concentration was moderately correlated with those of the 8:2 FTSA, 6:2 Cl-PFAES, and 8:2 ClPFAES $(R=0.263-0.372, P<0.05)$. Significant correlations between the PFAS concentrations could indicate common release pathway and/or similar fate of the monitored compounds during the WWTP processes. Moreover, a strong correlation was also found between the residue levels of $6: 2 \mathrm{Cl}$ PFAES and 8:2 Cl-PFAES $(R=0.849, P<0.01)$, which further indicates the association between the two chemicals from industrial manufacturing and/or commercial application. Nevertheless, no obvious relationship was observed between individual fluoroalkyl sulfonate concentration and total carbon content (TOC) in the sludge samples. Investigations on mass flows in wastewater treatment facilities around the world suggested that the fate of PFAS in WWTP processes is case dependent and that adsorption of PFAS onto the organic phase of sludge might not be the predominant removal mechanism. ${ }^{30}$ Moreover, the impact of different WWTP sludge treatment techniques (anaerobic-anoxic-oxic, anoxic/oxic, oxidation ditch, and sequencing batch reactor) on the log-transformed PFSA concentrations was not observed in this study (Figure S4, oneway ANOVA, $P>0.05)$.

Relative Abundances of 6:2/8:2 Cl-PFAES in Commercial Product and Sludge Samples. Both 6:2 and 8:2 ClPFAES were positively identified as the major components in the purchased commercial F-53B product, and the 6:2/8:2 ClPFAES content ratios were measured by quantitative analysis of the diluted solution of the product powder at concentrations within the LC-MS/MS linearity range (spiked at 0.5, 1.0, 2.0, 5.0, 10, 20, and $50 \mu \mathrm{g} / \mathrm{mL}, n=5$ for each spiked level). The measured average 6:2/8:2 Cl-PFAES ratios were $12.9 \pm 2.6$ in the commercial product, which are significantly different $(4.5 \pm$ 2.7, $n=50$, Figure 3A) from those in the sludge samples with quantifiable levels (i.e., 6:2 and 8:2 concentration > MQLs). The trend was further confirmed by separately investigating the 6:2/8:2 Cl-PFAES ratio in sludge samples grouped by the $6: 2$ Cl-PFAES concentrations (Figure 3B). Compared with those in the commercial product, discrete 6:2/8:2 Cl-PFAES ratios were all obtained in the grouped sludge samples $(2.4 \pm 0.9,4.1 \pm$ $1.6,4.9 \pm 2.2$, and $6.7 \pm 3.1$ for 6:2 Cl-PFAES concentration groups $<1,1-2,2-5$, and $>5 \mathrm{ng} / \mathrm{g}$, respectively). This phenomenon could partly be related to the differences in physical-chemical properties and fate of different fluoroalkyl sulfonates in the environment. For instance, PFDS was observed to have the highest sediment-water distribution coefficient among the investigated PFSA homologues (C4C10), ${ }^{32,39}$ suggesting increased adsorption ability along with higher hydrophobic characteristic.

Environmental Implications. Both 6:2 Cl-PFAES and PFOS showed similar environmental behaviors such as biodegradation resistance and moderate toxicology effects. ${ }^{16}$ Thus, the identification of $8: 2$ and 10:2 Cl-PFAESs in the sludge samples calls for investigation on potential impacts of these emerging PFAES analogues. Compared with the molecular structures of PFSAs, the additional unique chlorine $\left(\mathrm{Cl}^{-}\right)$and ether-substituted (C-0-C) functional groups in the Cl-PFAESs might contribute positively to their hydrophobic properties (Tables S4 and S5; EPI Suite V4.11 ${ }^{40}$ ).The specific 

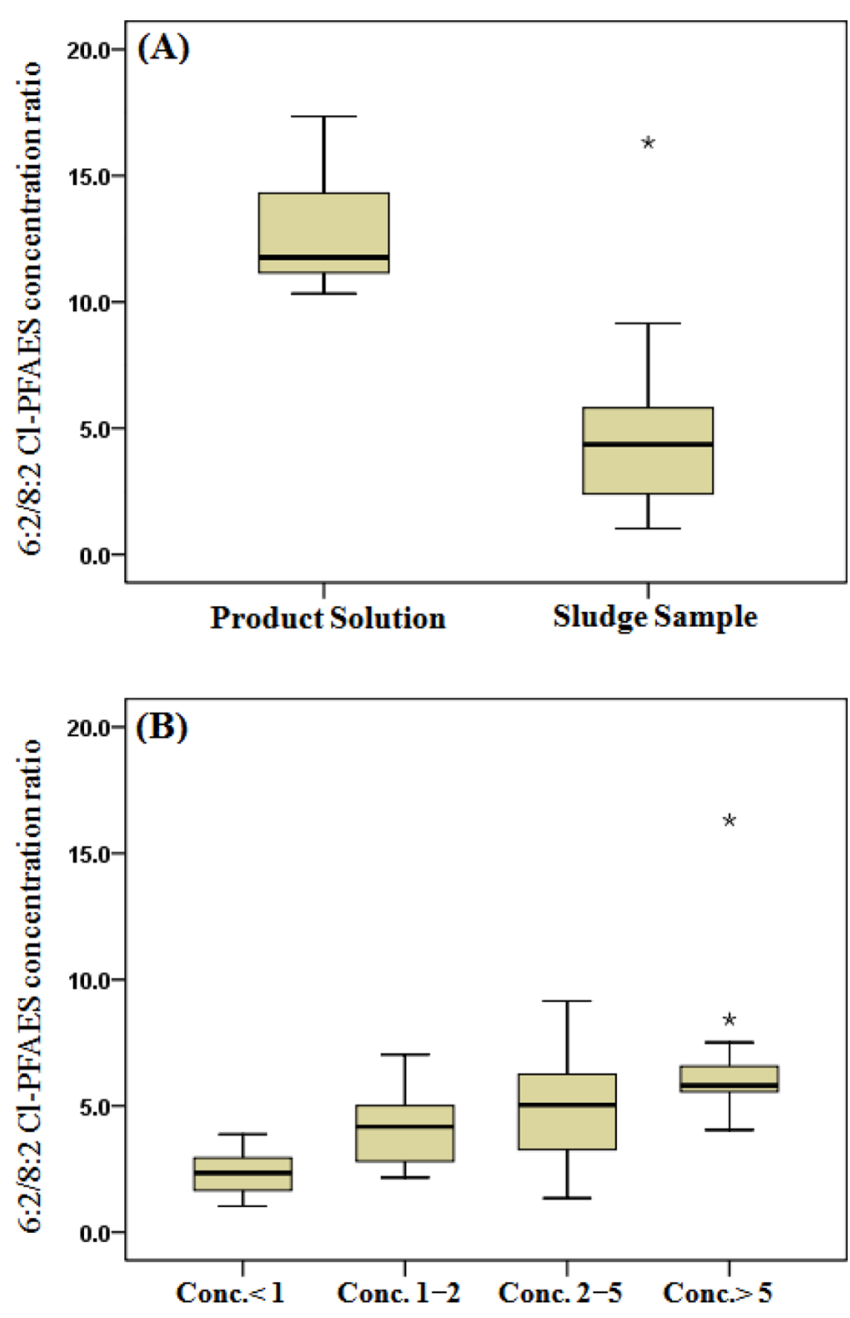

Figure 3. 6:2/8:2 Cl-PFAES concentration ratios in the commercial F$53 \mathrm{~B}$ product and the sludge samples. (A) 6:2/8:2 Cl-PFAES ratios in product solution (spiked at $0.5,1.0,2.0,5.0,10,20$, and $50 \mu \mathrm{g} / \mathrm{mL}, n=$ 5 in each spiked level) and all sludge samples $(n=50$, samples were taken into account only when both $6: 2$ and 8:2 Cl-PFAES concentrations surpass the corresponding MQLs). (B) 6:2/8:2 ClPFAES concentration ratios in the grouped sludge samples (samples were divided according to the 6:2 Cl-PFAES concentration, and the number of samples in the Conc. $<1$, Conc. 1-2, Conc. 2-5, and Conc. $>5$ groups were $n=14,9,14$, and 13 , respectively).

$\mathrm{BCF} / \mathrm{BAF}$ values of fluorinated substances could not be accurately estimated by current quantitative structure-property relationship models due to the nonlinear concentrationdependent adsorption mechanism. ${ }^{41}$ However, higher relative proportion of C10 fluorinated compounds such as PFDS and 8:2 FTSA in biota and human blood samples ${ }^{9,35,42}$ further substantiate the increasing bioaccumulation potential of longchain fluoroalkyl sulfonates. Hence, biological uptake and accumulation of 6:2 and 8:2 Cl-PFAESs are highly possible.

Moreover, laboratory and field research on the environmental fate and toxicological effects of polyfluorinated chemicals also revealed discrepant behaviors among different PFSA analogues. For instance, increasing bioaccumulation factors were observed with increased carbon-chain lengths (i.e., PFBS, PFHxS, and PFOS) in aqueous and terrestrial species. ${ }^{8,9}$ Acute embryo toxicology on Xenopus laevis ${ }^{43}$ and intercellular communication inhibition in subchronic bacterial exposure of $\mathrm{PFOS}^{44}$ were more obvious compared with those of PFBS and PFHxS. Multiple end point assays in vitro further suggested that the adverse effects are more influenced by the fluorinated carbon chain than the different functional groups. ${ }^{45}$ Therefore, empirical studies on the fate and potential adverse effects of the newly identified Cl-PFAES analogues are warranted in order to better elucidate their behaviors in the environment.

\section{ASSOCIATED CONTENT}

S Supporting Information

Laboratory-purification procedures of the 6:2 and 8:2 ClPFAES standards from the commercial F-53B mist suppressant product; (Table S1) detailed information on the wastewater treatment plant characteristics; (Table S2) measured accurate mass and corresponding theoretical mass of the molecular ion and characteristic fragmentation ion for each PFAES analogues in the sludge samples; (Table S3) LC-MS/MS instrument parameters and method quantification limits for the separation and quantification of the target analytes; (Tables S4 and S5) details of the "fragment constant" methodology in the KOWWIN model; (Figure S1) sampling locations, spatial concentrations, and composition profiles of Cl-PFAES homologues in municipal sewage sludge samples in China; (Figure S2) $\mathrm{MS}^{2}$ characteristic fragmentation ions of the 6:2 ClPFAES standard in the HCD mode; (Figure S3) instrument responses $(n=3)$ of $\left[\mathrm{M}\left({ }^{35} \mathrm{Cl}\right)\right]^{-}$molecular ions for 6:2 and 8:2 Cl-PFAESs in the HRMS full scan spectrum; (Figure S4) the score plots (PC1 versus PC2) of analyte concentrations in the sewage sludge samples grouped by WWTP treatment techniques; (Figure S5) separation and collection of the elute fractions of the 6:2 and 8:2 Cl-PFAES in the Autopurificaion system; (Figures S6-S11) detailed information on the NMR $\left({ }^{19} \mathrm{~F}\right.$ and $\left.{ }^{12} \mathrm{C} \mathrm{NMR}\right)$ and purity results of the laboratory-purified 6:2 and 8:2 Cl-PFAES standards. The Supporting Information is available free of charge on the ACS Publications website at DOI: 10.1021 /acs.est.5b01010.

\section{AUTHOR INFORMATION}

\section{Corresponding Author}

*Tel: 8610-6284-9334. Fax: 8610-6284-9179. E-mail: gbjiang@ rcees.ac.cn.

\section{Notes}

The authors declare no competing financial interest.

\section{ACKNOWLEDGMENTS}

This work was jointly supported by the National Basic Research Program of China (2015CB453102), the National Natural Science Foundation (21361140359, 21207140), and the Strategic Priority Research Program of the Chinese Academy of Sciences (XDB14010400).

\section{REFERENCES}

(1) Kissa, E. Fluorinated Surfactants and Repellants, 2nd ed.; Marcel Dekker Inc.: New York, 2001.

(2) Buck, R. C.; Franklin, J.; Berger, U.; Conder, J. M.; Cousins, I. T.; Voogt, P.; Jensen, A. A.; Kannan, K.; Mabury, S. A.; Leeuwen, S. P. J. Perfluoroalkyl and polyfluoroalkyl substances in the environment: Terminology, classification, and origins. Integr. Environ. Assess. Manage. 2011, 7 (4), 513-541 DOI: 10.1002/ieam.258.

(3) Paul, A. G.; Jones, K. C.; Sweetman, A. J. A first global production, emission, and environmental inventory for perfluorooctane sulfonate. Environ. Sci. Technol. 2009, 43 (2), 386-392 DOI: $10.1021 /$ es802216n. 
(4) Wang, Z.; Cousins, I. T.; Scheringer, M.; Buck, R. C.; Hungerbühler, K. Global emission inventories for $\mathrm{C} 4-\mathrm{C} 14$ perfluoroalkyl carboxylic acid (PFCA) homologues from 1951 to 2030, part II: The remaining pieces of the puzzle. Environ. Int. 2014, 69, 166-176 DOI: $10.1016 /$ j.envint.2014.04.006.

(5) Jahnke, A.; Berger, U.; Ebinghaus, R.; Temme, C. Latitudinal gradient of airborne polyfluorinated alkyl substances in the marine atmosphere between Germany and South Africa $\left(53^{\circ} \mathrm{N}-33^{\circ} \mathrm{S}\right)$. Environ. Sci. Technol. 2007, 41 (9), 3055-3061 DOI: 10.1021/ es062389h.

(6) Houde, M.; Martin, J. W.; Letcher, R. J.; Solomon, K. R.; Muir, D. C. G. Biological monitoring of polyfluoroalkyl substances: A review. Environ. Sci. Technol. 2006, 40 (11), 3463-3473 DOI: 10.1021/ es052580n.

(7) Young, C. J.; Furdui, V. I.; Franklin, J.; Koerner, R. M.; Muir, D. C. G.; Mabury, S. A. Perfluorinated acids in Arctic snow: New evidence for atmospheric formation. Environ. Sci. Technol. 2007, 41 (10), 3455-3461 DOI: 10.1021/es0626234.

(8) Zhao, S. Y.; Zhu, L. Y.; Liu, L.; Liu, Z. T.; Zhang, Y. H. Bioaccumulation of perfluoalkyl carboxylates (PFCAs) and perfluoalkane Sulfonates (PFSAs) by earthworms (Eisenia fetida) in soil. Environ. Pollut. 2013, 179, 45-52 DOI: 10.1016/j.envpol.2013.04.002.

(9) Pan, C. G.; Zhao, J. L.; Liu, Y. S.; Zhan, Q. Q.; Chen, Z. F.; Lai, H. J.; Peng, F. J.; Liu, S. S.; Ying, G. G. Bioaccumulation and risk assessment of per- and polyfluoroalkyl substances in wild freshwater fish from rivers in the Pearl River Delta region, South China. Ecotoxicol. Environ. Saf. 2014, 107, 192-199 DOI: 10.1016/ j.ecoenv.2014.05.031.

(10) Lau, C.; Anitole, K.; Hodes, C.; Lai, D.; Pfahles-Hutchens, A.; Seed, J. Perfluoroalkyl acids: A review of monitoring and toxicological findings. Toxicol. Sci. 2007, 99 (2), 366-394 DOI: 10.1093/toxsci/ $\mathrm{kfm} 128$.

(11) UNEP. SC-4/17: Listing of perfluorooctane sulfonic acid, its salts and perfluorooctane sulfonyl fluoride, COP-4; Stockholm Convention on Persistent Organic Pollutants, United Nations Environment Programme, 2009.

(12) Xie, S. W.; Wang, T. Y.; Liu, S. J.; Jones, K. C.; Sweetman, A. J.; $\mathrm{Lu}, \mathrm{Y}$. L. Industrial source identification and emission estimation of perfluooctane sulfonate in China. Environ. Int. 2013, 52, 1-8 DOI: 10.1016/j.envint.2012.11.004.

(13) UNEP. POPRC-8/8: Perfluooctane sulfonic acid, its salts, perfluooctane sulfonyl fluoride and their related chemicals in open applications; Stockholm Convention on Persistent Organic Pollutants, United Nations Environment Programme, 2012.

(14) UNEP. Technical paper on the identification and assessment of alternatives to the use of perfluorooctane sulfonic acid in open applications (UNEP/POPS/POPRC.8/INF/17); Stockholm Convention on Persistent Organic Pollutants, United Nations Environment Programme, 2012.

(15) Shanghai Guangming Electroplating Plant; Shanghai Institute of Organic Chemistry at Chinese Academy of Sciences. Jiangsu Taizhou Electrochemical Plant.. Preparation of F-53 and its application in chrome mist suppression. Mater. Prot. 1976, 3 (3), 27-32.

(16) Wang, S. W.; Huang, J.; Yang, Y.; Hui, Y. M.; Ge, Y. X.; Larssen, T.; Yu, G.; Deng, S. B.; Wang, B.; Harman, C. First report of a Chinese PFOS alternative overlooked for 30 years: Its toxicity, persistence, and presence in the environment. Environ. Sci. Technol. 2013, 47 (18), 10163-10170 DOI: $10.1021 /$ es401525n.

(17) Schultz, M. M.; Higgins, C. P.; Huset, C. A.; Luthy, R. G.; Barofsky, D. F.; Field, J. A. Fluorochemical mass flows in a municipal wastewater treatment facility. Environ. Sci. Technol. 2006, 40 (23), 7350-7357 DOI: 10.1021/es061025m.

(18) Ahrens, L.; Shoeib, M.; Harner, T. Wastewater treatment plant and landfills as sources of polyfluoroalkyl compounds to the atmosphere. Environ. Sci. Technol. 2011, 45 (19), 8098-8105 DOI: $10.1021 /$ es1036173.

(19) Ruan, T.; Liu, R. Z.; Fu, Q.; Wang, T.; Wang, Y. W.; Song, S. J.; Wang, P.; Teng, M.; Jiang, G. B. Concentrations and composition profiles of benzotriazole UV stabilizers in municipal sewage sludge in
China. Environ. Sci. Technol. 2012, 46 (4), 2071-2079 DOI: 10.1021/ es203376x.

(20) Powley, C. R.; George, S. W.; Ryan, T. W.; Buck, R. C. Matrix effect-free analytical methods for determination of perfluorinated carboxylic acids in environmental matrixes. Anal. Chem. 2005, 77 (19), 6353-6358 DOI: 10.1021/ac0508090.

(21) Wang, N.; Liu, J.; Buck, R. C.; Korzeniowski, S. H.; Wolstenholme, B. W. Folsom, P.W.; Sulecki, L.M. 6:2 Fluorotelomer sulfonate aerobic biotransformation in activated sludge of waste water treatment plants. Chemosphere 2011, 82, 853-858 DOI: 10.1016/ j.chemosphere.2010.11.003.

(22) Ruan, T.; Lin, Y. F.; Wang, T.; Jiang, G. B.; Wang, N. Methodology for studying biotransformation of polyfluoroalkyl precursors in the environment. TrAC Trends Anal. Chem. 2015, DOI: $10.1016 /$ j.trac.2014.11.017.

(23) Sun, H. W.; Gerecke, A. C.; Giger, W.; Alder, A. C. Long-chain perfluorinated chemicals in digested sewage sludges in Switzerland. Environ. Pollut. 2011, 159 (2), 654-662 DOI: 10.1016/j.envpol.2010.09.020.

(24) Bossi, R.; Strand, J.; Sortkjaer, O.; Larsen, M. M. Perfluoroalkyl compounds in Danish wastewater treatment plants and aquatic environments. Environ. Int. 2008, 34 (4), 443-450 DOI: 10.1016/ j.envint.2007.10.002.

(25) IVL. Results from the Swedish National Screening Programme 2005. Sbureport 3: Perfluorinated alkylated substances (PFAS); IVL Swedish Environmental Research Institute Ltd, 2006; http://www3.ivl. se/rapporter/pdf/B1698.pdf (assessed on 31th, January, 2015).

(26) D'eon, J. C.; Crozier, P. W.; Furdui, V. I.; Reiner, E. J.; Libelo, E. L.; Mabury, S. A. Perfluorinated phosphonic acids in Canadian surface waters and wastewater treatment plant effluent: Discovery of a new class of perfluorinated acids. Environ. Toxicol. Chem. 2009, 28 (10), 2101-2107 DOI: 10.1897/09-048.1.

(27) Higgins, C. P.; Field, J. A.; Criddle, C. S.; Luthy, R. G. Quantitative determination of perfluorochemicals in sediments and domestic sludge. Environ. Sci. Technol. 2005, 39 (11), 3946-3956 DOI: $10.1021 /$ es048245p.

(28) Chen, H.; Zhang, C.; Han, J. B.; Yu, Y. X.; Zhang, P. PFOS and PFOA in influents, effluents, and biosolids of Chinese wastewater treatment plants and effluent-receiving marine environments. Environ. Pollut. 2012, 170, 26-31 DOI: 10.1016/j.envpol.2012.06.016.

(29) Pan, Y. Y.; Shi, Y. L.; Wang, J. M.; Cai, Y. Q. Evaluation of perfluorinated compounds in seven wastewater treatment plants in Beijing urban areas. Sci. China Chem. 2011, 54 (3), 552-558 DOI: $10.1007 / \mathrm{s} 11426-010-4093-x$.

(30) Campo, J.; Masiá, A.; Picó, Y.; Farré, M.; Barceló, D. Distribution and fate of perfluorlkyl substances in Mediterranean Spanish sewage treatment plants. Sci. Total Environ. 2014, 472, 912922 DOI: $10.1016 /$ j.scitotenv.2013.11.056.

(31) Yu, J.; Hu, J. Y.; Tanaka, S.; Fujii, S. Perfluorooctane sulfonate (PFOS) and perfluorooctanoic acid (PFOA) in sewage treatment plants. Water Res. 2009, 43 (9), 2399-2408 DOI: 10.1016/ j.watres.2009.03.009.

(32) Higgins, C. P.; Luthy, R. G. Sorption of perfluorinated surfactants on sediments. Environ. Sci. Technol. 2006, 40 (23), 7251-7256 DOI: 10.1021/es061000n.

(33) Gao, Y.; Fu, J. J.; Zeng, L. X.; Li, A.; Li, H. J.; Zhu, N. L.; Liu, R. Z.; Liu, A. F.; Wang, Y. W.; Jiang, G. B. Occurrence and fate of Perfluoroalkyl substances in marine sediments from the Chinese Bohai Sea, Yellow Sea, and East China Sea. Environ. Pollut. 2014, 194, 60-68 DOI: 10.1016/j.envpol.2014.07.018.

(34) Bijlsma, L.; Emke, E.; Hernández, F.; de Voogt, P. Performance of the linear ion trap Orbitrap mass analyzer for qualitative and quantitative analysis of drugs of abuse and relevant metabolites in sewage water. Anal. Chim. Acta 2013, 768, 102-110 DOI: 10.1016/ j.aca.2013.01.010.

(35) Loi, E. I. H.; Yeung, L. W. Y.; Mabury, S. A.; Lam, P. K. S. Detections of commercial fluorosurfactants in Hong Kong marine environment and human blood: A pilot study. Environ. Sci. Technol. 2013, 47 (9), 4677-4685 DOI: 10.1021/es303805k. 
(36) Backe, W. J.; Day, T. C.; Field, J. A. Zwitterionic, cationic and anionic fluorinated chemicals in aqueous film forming foam formulations and groundwater from U.S. military bases by nonaqueous large-volume injection HPLC-MS/MS. Environ. Sci. Technol. 2013, 47 (15), 5226-5234 DOI: 10.1021/es3034999.

(37) Weiner, B.; Yeung, L. W. Y.; Marchington, E. B.; D’Agostino, L. A.; Mabury, S. A. Organic fluorine content in aqueous film forming foams (AFFFs) and biodegradation of the foam component 6:2 fluorotelomermercaptoalkylamido sulfonate (6:2 FTSAS). Environ. Sci. 2013, 10, 486-493 DOI: 10.1071/EN13128.

(38) Place, B. J.; Field, J. A. Identification of novel fluorochemicals in aqueous film-forming foams used by the US military. Environ. Sci. Technol. 2012, 46 (13), 7120-7127 DOI: 10.1021/es301465n.

(39) Pico, Y.; Blasco, C.; Farré, M.; Barceló, D. Occurrence of perfluorinated compounds in water and sediment of L'Albufera Natural Park (València, Spain). Environ. Sci. Pollut. Res. 2012, 19 (4), 946-957 DOI: 10.1007/s11356-011-0560-y.

(40) US EPA. Exposure Assessment Tools and Models, Estimation Program Interface (EPI) Suite, V 4.11; U.S. Environmental Protection Agency, Exposure Assessment Branch: Washington, DC, 2012.

(41) Liu, C. H.; Gin, K. Y. H.; Chang, V. W. C.; Goh, B. P. L.; Reinhard, M. Novel perspectives on the bioaccumulation of PFCs-the concentration dependency. Environ. Sci. Technol. 2011, 45 (22), 97589764 DOI: $10.1021 /$ es202078n.

(42) Lee, H.; Mabury, S. A. A pilot survey of legacy and current commercial fluorinated chemicals in human sera from United States donors in 2009. Environ. Sci. Technol. 2011, 45 (22), 8067-8074 DOI: $10.1021 /$ es200167q.

(43) Wei, R. G.; Su, H. Q.; Qin, Z. F. Developmental toxicity of perfluorooctane sulfonate, perfluorohexane sulfonate and perfluorobutane sulfonate to Xenopus Embryos. Asian J. Ecotoxicol. 2012, 7 (5), $542-548$.

(44) Hu, W. Y.; Jones, P. D.; Upham, B. L.; Trosko, J. E.; Lau, C.; Giesy, J. P. Inhibition of gap junctional intercellular communication by perfluorinated compounds in rat liver and dolphin kidney epithelial cell lines in vitro and Sprague-Dawley rats in vivo. Toxicol. Sci. 2002, 68 (2), 429-436 DOI: 10.1093/toxsci/68.2.429.

(45) Nobels, I.; Dardenne, F.; De Coen, W.; Blust, R. Application of a multiple endpoint bacterial reporter assay to evaluate toxicological relevant endpoints of perfluorinated compounds with different functional groups and varying chain length. Toxicol. In Vitro 2010, 24 (6), 1768-1774 DOI: 10.1016/j.tiv.2010.07.002. 